\title{
Research Paper: The Effect of Quantitative Electroencephalography-Based Neurofeedback Therapy on Anxiety, Depression, and Emotion Regulation in People with Generalized Anxiety Disorder
}

\author{
Hassan Abdian' ${ }^{1}$ (D), Mazaher Rezaei ${ }^{1}$ (D), Zakaria Eskandari² (D, Shokoufeh Ramezani ${ }^{3}$ (D), Reza Pirzeh ${ }^{4}$ (D), Mohsen Dadashi ${ }^{5 *}$ (1) \\ 1. Department of Clinical Psychology, Faculty of Medicine, Zanjan University of Medical Sciences, Zanjan, Iran. \\ 2. Department of Clinical Psychology and Addiction Studies, Faculty of Medicine, Zanjan University of Medical Sciences, Zanjan, Iran. \\ 3. Department of Educational Sciences, Faculty of Humanity, University of Mohaghegh Ardabili, Ardabil, Iran. \\ 4. Department of Pschiatry, Faculty of Medicine, Zanjan University of Medical Sciences, Zanjan, Iran. \\ 5. Department of Clinical Psychology, Social Determinants of Health Research Center, Zanjan University of Medical Sciences, Zanjan, Iran.
}

$\begin{aligned} & \text { Use your device to scan } \\ & \text { and read the article online }\end{aligned}$
Electroencephalography-Based Neurofeedback Therapy on Anxiety, Depression, and Emotion Regulation in People with Gener-
alized Anxiety Disorder. Basic and Clinical Neuroscience, 12(2), 281-290. http://dx.doi.org/10.32598/bcn.12.2.2378.1
dol'http://dx.doi.org/10.32598/bcn.12.2.2378.1

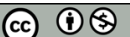

Article info:

Received: 06 Apr 2020

First Revision: 13 Dec 2020

Accepted: 10 Feb 2021

Available Online: 01 Mar 2021

Keywords:

Quantitative

electroencephalography,

Neurofeedback, Generalized anxiety disorder, depression,

Emotion regulation

\section{A B S T RA C T}

Introduction: Generalized Anxiety Disorder (GAD) is one of the most common anxiety disorders that has significant adverse effects on social functioning, occupational/academic performance, and daily living. This study aimed to evaluate the effect of Quantitative Electroencephalography (QEEG)-based Neurofeedback (NFB) therapy on anxiety, depression, and emotion regulation of people with GAD.

Methods: This research is a quasi-experimental study with a pre-test/post-test/follow-up design and a control group. The study participants were 29 college students with GAD living in Zanjan City, Iran, who were selected using a convenience sampling method. Then, they were randomly divided into two groups of intervention $(n=15)$ and control $(n=14)$. The protocol of NFB therapy was designed based on the QEEG method. The intervention group received QEEG-based NFB therapy for 8 weeks ( 20 sessions, 2 sessions per week, each session for $45 \mathrm{~min}$ ), while the control group received no intervention. The samples were surveyed and measured by using a 7-item GAD scale, Emotion Regulation Questionnaire (ERQ), 21-item Depression, Anxiety, and Stress Scale (DASS), and Structured Clinical Interview for DSM (SCID) before and after the intervention and then at a 3-month follow-up. The collected data were analyzed in SPSS software V. 22 using univariate ANCOVA and repeated measures ANOVA.

Results: The within-subjects effect of time (pre-test, post-test, and follow-up) was statistically significant $(\mathrm{P}=0.031)$. The intervention group showed significant changes in the post-test and follow-up phases in comparison with the control group. The anxiety and depression levels of patients reduced significantly $(\mathrm{P}=0.001)$, and their emotion regulation improved $(\mathrm{P}=0.001)$ after the intervention, and they remained unchanged in the follow-up period.

Conclusion: QEEG-based NFB therapy can reduce anxiety and depression and improve emotion regulation in patients with GAD.

"Corresponding Author:

Mohsen Dadashi, PhD.

Address: Department of Clinical Psychology, Social Determinants of Health Research Center, Zanjan University of Medical Sciences, Zanjan, Iran. Tel: +98 (912) 7433559

E-mail:psy.mohsen@gmail.com 


\section{Highlights}

- Electroencephalography-Based Neurofeedback Therapy is effective in reducing the signs and symptoms of generalized anxiety disorder.

- Electroencephalography-Based Neurofeedback Therapy is effective in reducing the signs and symptoms of depressive disorder.

- Electroencephalography-Based Neurofeedback Therapy improved emotion regulation in people with generalized anxiety disorder.

\section{Plain Language Summary}

Generalized Anxiety Disorder (GAD) is one of the most common anxiety disorders that have significant adverse effects on social functioning, occupational/academic performance, and daily living. The pathological understanding of neurological and psychiatric states has been considered in recent decades, and significant results have been reported on Quantitative Electroencephalography (QEEG) of these disorders. QEEG is a method for examining brain waves, which involves using computers and power spectral analysis of brain waves. In this study, we wanted to evaluate the Effect of Quantitative Electroencephalography-Based Neurofeedback Therapy on Anxiety, Depression, and Emotion Regulation in People with Generalized Anxiety Disorder. The results showed that Electroencephalography-Based Neurofeedback Therapy affected psychological disorders.

\section{Introduction}

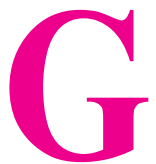

eneralized Anxiety Disorder (GAD) is one of the most common anxiety disorders that has significant adverse effects on social functioning, occupational/academic performance, and daily living. The main characteristic of this disorder is excessive worry and anxiety about ordinary life events and activities such as occupational responsibilities, financial issues, self-health, and the health of other family members (DSM-5, American Psychiatric Association, 2013). It is difficult for the affected people to control their anxiety and prevent disturbing thoughts from interfering with their daily lives. Besides, they experience some physical symptoms, including restlessness, early fatigue, muscle tension, difficulty concentrating, irritability, and sleep disorders (DSM-5, American Psychiatric Association, 2013). The fifth edition of the Diagnostic and Statistical Manual of Mental Disorders (DSM-5) reported the 12-month prevalence of GAD as $0.9 \%$ among adolescents and $2.9 \%$ among adults in the US. The prevalence of this disorder in other countries ranges from $0.4 \%$ to $3.6 \%$. Also, women are two times more likely to develop the disorder (DSM-5, American Psychiatric Association, 2013).

Emotion regulation refers to modulating emotional experiences, understanding and accepting emotions, and behaving toward desired goals, regardless of so- cial norms (Jakupcak, Salters, Gratz, \& Roemer, 2003). Maladaptive emotion regulation strategies reduce one's mental health and well-being (Aldao \& Nolen-Hoeksema, 2010). Patients with GAD experience are increasing difficulty learning to regulate and manage their emotions than the control group and people with other comorbid disorders such as social anxiety and depression (Turk, Heimberg, Luterek, Mennin, \& Fresco, 2005). The emotion dysregulation model of GAD emphasizes that affected individuals experience positive and negative emotions with more intensity than others. They have a poorer understanding of their emotions, consider emotions as bothersome and threatening, and eventually employ ineffective emotion regulation strategies (Mennin, Heimberg, Turk, \& Fresco, 2005). On the other hand, given the available information about the brain and observing brain activity, therapists increasingly emphasize brain-focused treatments. Recent advances imply recognizing functional brain abnormalities in anxiety disorders, including GAD (Heller, Etienne, \& Miller, 1955; Wiedemann et al., 1999; Brown, Scheflin, \& Hammond, 1998; Simpson, Tenke, Towey, Liebowitz, \& Bruder 2000; Kuskowski et al., 1993).

The pathological understanding of neurological and psychiatric states has been considered in recent decades, and significant results have been reported on Quantitative Electroencephalography (QEEG) of these disorders (Demos \& Masterpasqua 2005). Heller, Etienne, \& Miller, 
(1995) studied Electroencephalography (EEG) frequencies in patients with anxiety disorders. They reported decreased EEG slow-wave activity in cortical atrophy and increased EEG beta-band activity before drug therapy. There is some evidence suggesting functional brain abnormalities in anxiety disorders, including GAD, panic disorder, post-traumatic stress disorder, and obsessivecompulsive disorder (Wiedemann et al., 1999; Simpson, Tenke, Towey, Liebowitz, \& Bruder, 2000).

QEEG is a method for examining brain waves, which involves using computers and power spectral analysis of brain waves (Thatcher, 2010). This method is different from the traditional or visual analysis of brain waves commonly used by neurologists. In QEEG, brain waves are recorded and analyzed using a mathematical method called "Fourier transform" in the frequency spectrum, and the power and dominance of each brain frequency are calculated separately. Traditional or visual analysis of brain waves has much lower reliability and validity of $9 \%$ to $29 \%$, even among specialists. However, QEEG's reliability and validity are above $90 \%$ and is used more widely in clinical settings (Thatcher, 2010).

Neurofeedback (NFB) therapy is an operant conditioning-based technique and a brain training method. According to Kandel et al. (2000), learning and conditioning are represented by chemical and structural changes in neurons and increasing or decreasing the total number of synapses between neurons. Also, the number and percentage of active synapses between neurons and chemical and even genetic background can alter the neurons' message transmission; thereby, learning, conditioning, and even memory in the brain are represented. These changes are manifested in functional form, so the impact of NFB therapy on brain function and performance can be measured and evaluated through QEEG. Considering the above materials, we aimed to evaluate the effect of QEEG-based NFB therapy on the anxiety, depression, and emotion regulation strategies in people with GAD.

\section{Methods}

This research is a quasi-experimental study with a pretest/post-test/follow-up design and a control group. This research is a registered clinical trial with code: IRCT IRCT20171102037181N1, approved by the Research Ethics Committee of Zanjan University of Medical Sciences (Code: ZUMS.REC.1396.138). The study population consisted of all college students with GAD in Zanjan City, Iran. The volunteers were selected who were aged 18-50 years at all academic levels (undergraduate, postgraduate, $\mathrm{PhD}$.). They were screened for GAD us- ing the generalized anxiety disorder 7-item (GAD-7) (Spitzer, Kroenke, Williams, \& Löwe, 2006) scale in the universities or clinics of Shahid Beheshti Hospital in Zanjan City, Iran.

The inclusion criteria were having DSM-5 criteria for GAD diagnosed by a psychiatrist or a clinical psychologist, being 18-50 years old, and having consent to participate in the study. The exclusion criteria were having a psychotic disorder, using drugs, receiving psychological treatment at least 6 months before entering the study, using medications for at least one month before entering the study, showing personality disorders, suicidal ideation, and being absent more than two intervention sessions. A total of 30 participants were selected using a convenience sampling method and randomized into two groups of intervention and control. The intervention group received QEEG-based NFB therapy for 8 weeks (20 sessions, 2 sessions per week, each for 45 $\mathrm{min}$ ), while the control group received no intervention. The samples' brain maps were recorded at three time intervals before and after the intervention and a 3-month follow-up period. One student left the study, and the data from 29 participants (15 in the intervention group and 14 in the control group) were analyzed using univariate ANCOVA and repeated measure ANOVA in SPSS V. 22.

\subsection{Study tools}

\subsubsection{GAD-7 Scale}

It has 7 items and was designed by Spitzer et al. (2006) to diagnose GAD and the severity of clinical symptoms. Regarding the reliability of this instrument, a Cronbach alpha of 0.92 has been reported (Spitzer et al., 2006). Its Persian version has a Cronbach alpha of 0.85 reported by Naeinian, Shairi, Sharifi, and Hadian (2011).

\subsubsection{Emotion Regulation Questionnaire (ERQ)}

This questionnaire has 10 items and was designed to assess two emotion regulation strategies: cognitive reappraisal and expressive suppression (Gross \& John, 2003). The Cronbach alpha for the subscale of cognitive reappraisal is 0.79; for expressive suppression, 0.73; and for the entire questionnaire, 0.69 (Gross \& John, 2003). For the Iranian population, Besharat (2013) evaluated the psychometric properties of ERQ. In the study of Besharat (2013), the Cronbach alpha values of 0.87 and 0.90 were reported for cognitive reappraisal and expressive suppression, respectively. By confirmatory factor analysis, the acceptable values of fit indices were also obtained. 
2.1.3. Depression, Anxiety, and Stress Scale 21item (DASS-21)

Lovibond and Lovibond designed this questionnaire. It has 21 items: 7 items for every three subscales. The final score is obtained by summing up the scores of three subscales. Each item is rated on a scale from " $0=$ Did not apply to me at all to $3=$ Applied to me very much or most of the time". Higher scores represent lower mental health. For the Iranian population, they reported test-retest validity of $80 \%$ for depression, $76 \%$ for anxiety, and $77 \%$ for stress. They also reported the Cronbach alphas of 0.81 , 0.74 , and 0.75 for these three subscales, respectively.

\subsubsection{Structured Clinical Interview for DSM (SCID)}

It is a semi-structured diagnostic interview based on DSM-4. It has two types: SCID-I, which assesses the main psychiatric disorders (Axis 1), and SCID-II, which evaluates personality disorders (Axis 2) in the DSM-4. SCID is extensively used in psychiatric studies more than other standard diagnostic interviews. Sharifi Vandad et al. translated it to Persian using the back-translation method and measured its validity on 299 subjects aged 18-65 years referred to outpatient clinics and inpatient wards of three psychiatric hospitals of Ruzbeh, Imam Hossein, and Iran. They also measured its reliability using the test-retest method on 104 samples. The diagnostic agreement was moderate to good for most specific and overall diagnoses with a median kappa of $>0.6$. The overall agreement (total kappa) was 0.52 for all current diagnoses and 0.55 for all lifetime diagnoses. They reported acceptable validity and reliability of the Persian SCID.

\subsubsection{Quantitative Electroencephalography (QEEG)}

It is an EEG activity recording method using a computer instead of the traditional recording on paper. Data are analyzed and accessed separately with NeuroGuide and WinEEG applications. In this method, the raw EEG wave is broken down into four distinct frequencies using Fourier transforms. Then, the power and amplitude of each frequency are calculated, and finally, the obtained number is compared with the normative data. The standard deviation and $\mathrm{Z}$ score indicate normal EEG activity at each point and frequency.

\subsubsection{Neurofeedlback therapy}

Neurofeedback (NFB) or EEG biofeedback is a comprehensive treatment system that works directly with the brain. The NFB device separates the raw EEG waves received through the electrodes placed on the patient's head into different waves. These waves are delta, theta, alpha, and beta. During NFB training, the electrodes are placed on the scalp according to the international 1020 system. Usually, two electrodes are placed in areas where EEG activity is more aberrant than normal EEG activity. Reference and ground electrodes are also placed at the ear lobes. They do not hurt the brain. They simply transmit brainwave activity to the device. The patient sits in front of the computer and can see what a computer shows, like a video/computer game or two-column chart where one column represents inefficient brainwave activity, and the other represents efficient brainwave activity. In this condition, the patient focuses his attention on the computer screen. Noise is heard when inefficient activity slightly decreases, or efficient activity slightly increases. Initially, changes in brain waves are unstable, but with repeated sessions and gradual change of thresholds to inhibit inappropriate activity and enhance healthy brain activity by the therapist, stable changes gradually become conditional (Demos \& Masterpasqua, 2005).

\section{Results}

The results of the Kolmogorov-Smirnov test showed that data were normally distributed ( $\mathrm{P}>0.05)$, and Levene's test results supported the equality of variance assumption $(\mathrm{P}>0.05)$. Table 1 presents the demographic characteristics of the patients. The Chi-square test results showed no significant difference between study groups in terms of residency status, marital status, and educational level, and hence they were homogenous (Table 1). In terms of age, the independent t-test results also reported no significant difference between groups (Table 2).

The mean anxiety and depression scores in the samples decreased after the intervention, and their use of emotion regulation strategies improved compared to their pre-test scores. However, their scores almost remained unchanged in the follow-up period compared to their post-test scores (Table 3). After removing GAD severity at the pre-test phase, the results showed a significant difference between groups. Based on the ETA values, QEEG-based NFB therapy can explain $81 \%, 44 \%$, and $70 \%$ of the variance in anxiety, depression, and emotion regulation strategies, respectively (Table 4). The withingroup main effect of time (pre-test, post-test, and follow-up) was also statistically significant ( $\mathrm{P}=0.001)$ (Table 5). For pairwise comparisons, the nature of this effect was evaluated using the Bonferroni test. Their results are 
Table 1. Demographic characteristics of the patients and the Chi-squared test results

\begin{tabular}{|c|c|c|c|c|}
\hline \multirow{2}{*}{\multicolumn{2}{|c|}{ Variable }} & \multicolumn{2}{|c|}{ No. (\%) } & \multirow{2}{*}{ Sig. } \\
\hline & & Intervention Group & Control Group & \\
\hline \multirow{3}{*}{ Residency status } & Resident & $6(40)$ & $5(7.35)$ & \multirow{3}{*}{0.81} \\
\hline & & & & \\
\hline & Non-resident & $9(60)$ & $9(3.64)$ & \\
\hline \multirow{3}{*}{ Marital status } & Single & $13(7.86)$ & $10(4.71)$ & \multirow{3}{*}{0.31} \\
\hline & & & & \\
\hline & Married & $2(3.13)$ & $4(6.28)$ & \\
\hline \multirow{5}{*}{ Educational level } & Associate degree & $3(20)$ & $1(1.7)$ & \multirow{5}{*}{0.55} \\
\hline & Bachelor degree & $5(33.3)$ & $7(50)$ & \\
\hline & Master degree & $4(7.26)$ & $2(3.14)$ & \\
\hline & $\mathrm{PhD}$ & $3(20)$ & $4(6.28)$ & \\
\hline & Total & $15(100)$ & $14(100)$ & \\
\hline
\end{tabular}

NEUR:SCIENCE

Table 2. The mean and standard deviation of age and the independent t-test results

\begin{tabular}{ccccc}
\hline \multirow{2}{*}{ Variable } & \multicolumn{3}{c}{ Mean \pm SD } & \multirow{2}{*}{ Sig. } \\
\cline { 2 - 4 } & Intervention Group & Control Group & \multirow{2}{*}{0.05} \\
\hline Age, $y$ & $24.93 \pm 5.39$ & $25.35 \pm 6.67$ & NeUR
\end{tabular}

NEUR:SCIENCE

shown in Table 6. As can be seen, there was a significant relationship between the pre-test and post-test and between pre-test and follow-up scores. In other words, the mean anxiety and depression scores in the pre-test phase were significantly higher than those in the post-test and follow-up. Although their post-test scores were lower than their follow-up scores, the difference was not significant. Regarding the variable of emotion regulation, its mean score in the pre-test phase was significantly lower than its post-test and follow-up scores $(\mathrm{P}<0.01)$. Also, its post-test score was higher than its follow-up score, although this difference was not significant $(\mathrm{P}>0.01)$

\section{Discussion}

In the present study, 29 students with GAD participated. Fifteen $(51 \%)$ were in the intervention group (Mean \pm SD age $=24.93 \pm 5.39 \mathrm{y})$ and $14(48.3 \%)$ in the control group (Mean \pm SD age $=25.35 \pm 6.67 \mathrm{y}$ ). In the intervention group, we observed a decrease in mean depression and anxiety

Table 3. The mean and standard deviation of study variables in two study groups

\begin{tabular}{|c|c|c|c|c|}
\hline \multirow{2}{*}{ Group } & \multirow{2}{*}{ Variable } & \multicolumn{3}{|c|}{ Mean \pm SD } \\
\hline & & Pre-test & Post-test & Follow-up \\
\hline \multirow{3}{*}{ Control } & Anxiety & $13.85 \pm 4.01$ & $14.21 \pm 3.01$ & $13.78 \pm 3.80$ \\
\hline & Emotion regulation & $27.85 \pm 9.01$ & $24.50 \pm 7.71$ & $25.00 \pm 9.33$ \\
\hline & Depression & $19.92 \pm 4.56$ & $20.71 \pm 2.78$ & $20.50 \pm 4.25$ \\
\hline \multirow{3}{*}{ Intervention } & Anxiety & $14.60 \pm 3.31$ & $5.73 \pm 2.27$ & $7.06 \pm 2.18$ \\
\hline & Emotion regulation & $29.40 \pm 4.83$ & $45.26 \pm 7.26$ & $44.93 \pm 10.56$ \\
\hline & Depression & $16.60 \pm 4.37$ & $12.80 \pm 4.50$ & $12.00 \pm 3.46$ \\
\hline
\end{tabular}


Table 4. One-way ANCOVA results for anxiety, depression, and emotion regulation in the pre-test phase

\begin{tabular}{|c|c|c|c|c|c|c|c|}
\hline Variable & Source & Sum of Squares & df & Mean Square & $\mathbf{F}$ & Sig. & Partial Eta Squared \\
\hline \multirow{3}{*}{ Anxiety } & Pre-test & 85.094 & 1 & 85.094 & 17.532 & 0.001 & 0.403 \\
\hline & Group & 559.784 & 1 & 559.784 & 115.331 & 0.001 & 0.816 \\
\hline & Error & 126.197 & 26 & 4.854 & & & \\
\hline \multirow{3}{*}{ Depression } & Pre-test & 70.258 & 1 & 70.258 & 5.146 & 0.032 & 0.165 \\
\hline & Group & 283.933 & 1 & 283.933 & 20.795 & 0.001 & 0.444 \\
\hline & Error & 354.999 & 26 & 13.654 & & & \\
\hline \multirow{3}{*}{ Emotion regulation } & Pre-test & 277.346 & 1 & 277.346 & 5.838 & 0.023 & 0.183 \\
\hline & Group & 2882.637 & 1 & 2882.637 & 60.683 & 0.001 & 0.7 \\
\hline & Error & 1235.088 & 26 & 47.503 & & & \\
\hline
\end{tabular}

NEUR SCIENCE

Table 5. Results of repeated measures ANOVA for anxiety, depression, and emotion regulation

\begin{tabular}{ccccccc}
\hline Source & Sum of Squares & df & Mean Square & F & Sig. & Eta Squared \\
\hline Time (anxiety) & 209.393 & 1 & 209.393 & 46.984 & 0.01 & 0.63 \\
\hline Time $\times$ Group & 201600 & 1 & 201.600 & 45.235 & 0.01 & 0.626 \\
\hline Error & 120.331 & 27 & 4.457 & & & 0.240 \\
\hline Time (depression) & 581.793 & 1 & 581.793 & 8.548 & 0.007 & 0.400 \\
\hline Time $\times$ Group & 1224.552 & 1 & 1224.552 & 17.991 & 0.001 & 0.030 \\
Error & 1837.724 & 27 & 68.064 & & 0.001 & 0.318 \\
\hline Time (ER) & 38.364 & 1 & 38.364 & 5.261 & 12.565 & 0.03 \\
\hline Time $\times$ group & 91.629 & 1 & 91.629 & & & \\
\hline Error & 196.902 & 27 & 7.293 & & & \\
\hline
\end{tabular}

ER: Emotion Regulation.

NEUR SCIENCE

Table 6. The post hoc test results for pairwise comparison

\begin{tabular}{|c|c|c|c|c|c|c|c|c|c|}
\hline \multirow[t]{2}{*}{ Variable } & $\begin{array}{c}\text { Pre-test/Post- } \\
\text { test }\end{array}$ & $\begin{array}{l}\text { Pre-test/Follow- } \\
\text { up }\end{array}$ & $\begin{array}{c}\text { Post-test/Follow- } \\
\text { up }\end{array}$ & \multirow[t]{2}{*}{ Mean Dif. } & \multirow[t]{2}{*}{ Error } & \multirow[t]{2}{*}{ Sig. } & \multirow[t]{2}{*}{ Mean Dif. } & \multirow[t]{2}{*}{ Error } & \multirow[t]{2}{*}{ Sig. } \\
\hline & Mean Difference & Error & Sig. & & & & & & \\
\hline Anxiety & 4.41 & 101 & 0.001 & 3.93 & 0.89 & 0.001 & -0.48 & 0.400 & 0.72 \\
\hline $\begin{array}{l}\text { Depres- } \\
\text { sion }\end{array}$ & 3.80 & 0.85 & 0.040 & 4.60 & 0.75 & 0.002 & 0.80 & 0.067 & 0.001 \\
\hline $\begin{array}{l}\text { Emotion } \\
\text { regulation }\end{array}$ & -6.25 & 1.456 & 0.001 & -6.33 & 2.168 & 0.021 & -0.08 & 1.871 & 0.001 \\
\hline
\end{tabular}


and an increase in emotion regulation from the pre-test to post-test phase, but in the follow-up period, it remained unchanged. In the control group, scores remained almost unchanged from the pre-test to follow-up phase.

The possible reason for the NFB effect on reducing symptoms of persistent anxiety in patients with GAD is the self-regulation of brain activity by authorities based on a classical conditioning method that persists long after treatment (Hammond, 2005). Anxiety responses interact with the autonomic nervous system, and the balance between sympathetic and parasympathetic activities is mediated by NFB therapy, leading to a balance in autonomic nervous system functioning (Othmer, Othmer, \& Legarda, 2011). One of the consequences of a balanced central nervous system is reaching the optimal level in a state of adaptive arousal and reducing maladaptive anxiety. The effect of NFB therapy on reducing anxiety symptoms is through central nervous system self-regulation by optimally stimulating arousal levels. It can help the person control the blood flow to the brain (Othmer et al., 2011). In this case, brain training for creating optimal brainwaves has positive effects on the autonomic nervous system balance and physiological responses such as heart rate and anxiety level (Faridnia, Shojaei, \& Rahimi, 2012).

Examining the difference between the QEEG-based NFB group and the control group showed a decrease in the severity of anxiety in the post-test and 3-month follow-up. There was a significant difference between the mean post-test scores of anxiety after excluding the pre-test effect for the intervention group where the partial eta squared value showed that $81 \%$ of variations in anxiety was explained by the QEEG-based NFB therapy. This finding is consistent with the results of previous studies. There are three brain networks involved in emotion regulation processes: default-mode network, central executive network, and salience network (Menon, 2011). These three essential networks play a coordinating role for complex cognitive functions. They regulate brain functions to work optimally (Critchley, 2005). Some experts in NFB therapy assume that the improvement of default-mode network activity enhances one's ability to self-regulate neurological functions (Caria et al., 2007). The central executive network is activated to store and use memory information appropriately in situations where cognitive tasks are presented, and there is a need for a high level of executive performance. This network has impaired activity in most people with depression and anxiety, and other mental disorders (Menon, 2011). The salience network is responsible for integrating visual, physical, emotional, somatic, and automated information. It includes the anterior cingulate cortex and insula and subcortical areas such as the amygdala and abdominal mammary gland (Barreiros, Almeida, Baía, \& Castelo-Branco, 2019). These areas have impaired function in anxiety, depression, impulse control, and substance abuse (Menon, 2011). NFB therapy targeting low-frequency brainwaves (alpha-theta) results in an improved function of these neural networks and inhibits the activity of specific and determinant regions in the induction of overarousal (Caria et al., 2007). This method has been proven by examining its effect in the pre-test and post-test. Also, functional MRI images of brain regions at two time intervals have shown significant differences in post-test scores in terms of over-arousal reduction (Caria et al., 2007). The effectiveness of NFB therapy in amygdala fluctuation has been demonstrated by applying functional MRI in target areas in numerous studies. There is evidence of its positive effect on amygdala function fluctuations in creating an optimally functional state. An important question is whether NFB therapy can affect emotion regulation strategies through the amygdala. Studies have shown that NFB therapy targets amygdala fluctuations through the blood oxygen level (Young et al., 2018).

The present study reported a decrease in depression among GAD patients at post-test and 3-month followup. There was a significant difference between the mean post-test scores of depression after excluding the pre-test effect for the intervention group, where the partial eta squared value showed that $44 \%$ of variations in depression was explained by the QEEG-based NFB therapy. This result is consistent with the previous studies done by Dyck et al. (2011). People with severe anxiety symptoms and, consequently, low mood can be treated by sensorimotor rhythm frequency band amplification in the T4 region and alpha-theta frequency amplification in the Pforzheimer-Zeitung region (Dyck et al., 2011). Increased activity of the right prefrontal cortex compared to the left prefrontal cortex occurs in people with mood and emotional symptoms (Monk, 2008). Improvement in mood symptoms is associated with decreased right prefrontal cortex activity (Hölzel et al., 2013). Neurofeedback of EEG frontal alpha asymmetry improves emotional symptoms by decreasing or suppressing left frontal alpha power and increasing right frontal alpha power (Cha et al., 2014). Alpha wave power training is associated with cognitive performance enhancement (Paret et al., 2014), and increased over-regulation of alpha wave power is related to the improvement in mental rotation of non-clinical individuals (Angelakis et al., 2007; Zoefel, Huster, \& Herrmann, 2011). A study on NFB therapy in people to improve emotional symptoms showed that, in initial sessions, their anterior insular cortex was targeted. It is an area specific to emotional regulation (Young et 
al., 2018), and a decrease in the activity of the anterior insular cortex was observed (Young et al., 2014).

Another finding of our study was related to the effect of QEEG-based NFB therapy on emotion regulation of GAD patients at post-test and 3-month follow-up. The result showed a significant increase in emotion regulation after excluding the pre-test effect for the intervention group, where the partial eta squared value showed that $70 \%$ of variations in emotion regulation are explained by the QEEG-based NFB therapy. Moreover, our results showed that the within-subjects effect of time (pre-test, post-test, and follow-up) was significant. Hölzel et al. (2013) studied patients with GAD by restingstate functional MRIs of specific brain regions related to anxiety and emotional regulation. These areas included the amygdala, anterior cingulate cortex, ventromedial prefrontal cortex, ventrolateral frontal cortex, and dorsolateral prefrontal cortex. Their results showed their abnormal activity and function. In these people, high activity in the amygdala was positively correlated with severe anxiety (Hölzel et al., 2013). The ventromedial prefrontal cortex plays a prominent role in risk assessment, which is closely linked to limbic cortical structure abnormalities and exacerbates the symptoms of individuals with GAD (Etkin et al., 2010). Overall, decreased activity and interaction between the left amygdala and left dorsolateral prefrontal cortex and increased functional relationship of the right amygdala with insula and anterior temporal gyrus in subjects with GAD confirms brain abnormalities that interact with emotional processing and regulation pathways (Liu et al., 2015).

The emotional dysregulation model of GAD people comprises four main components (Mennin, Turk, Heimberg, \& Carmin, 2004). The first component emphasizes that people with GAD experience more emotional arousal. In other words, they experience emotions far more intense than normal people. This emotion sensitivity is related to both positive and negative affections, but negative affections seem to intensify. The second component is the poorer perception of self-emotions compared to normal people. The third component is their more negative attitude towards emotions. For example, to them, any emotion can be frightening. The final component is the use of inappropriate and maladaptive emotion regulation strategies, which ultimately make their emotional state worse than the initial state they were trying to get rid of (Borkovec, Ray, \& Stober, 1998). For example, they try to drastically reduce their emotions, control them completely, or inappropriately express their emotional arousals such as excessive worry, suppression of emotions, or even a burst of emotions. Therefore, excessive worry as an ineffective emotion regulation strategy plays an important role in this model. According to Menin et al., the involvement of these four components usually begins with the first component (emotion sensitivity) and then reaches from the second and third components to the fourth component. This process may also be activated in reverse order (Mennin et al., 2004).

QEEG-based NFB therapy is effective in reducing anxiety and depression and improving the use of emotion regulation strategies in GAD patients. Considering the two mentioned models and the mechanism of NFB therapy, this method can explain cognitive and biological models in a coordinated and interactive way. To achieve each of the components in these models, more systematic and coherent studies should focus on specific components and make lasting changes to them.

This study had some limitations and disadvantages. The first was the lack of random sampling technique, and instead, the convenience sampling method was used, which can affect the generalizability of study results. The second disadvantage was the lack of a placebo group and the use of combined pharmacological and psychological treatments. The small size of sample groups was another limitation that can affect the results. The lack of a novel tool to evaluate emotional regulation in brain structures was another limitation that could be done in specific brain areas, including the insula, cingulate, and amygdala, and provide more accurate information.

It is recommended that, in future studies, a random sampling technique and larger sample size be used so that the results could be generalizable. Using pharmacological and psychological treatments separately or in combination is recommended to provide greater accuracy in dosage and effect size of each intervention. Further studies are recommended to use functional MRI and corticomotor systems (for measuring cortical thickness) to quantify changes in physiological levels of the brain accurately.

\section{Ethical Considerations}

\section{Compliance with ethical guidelines}

This research is a registered clinical trial with code: IRCT IRCT20171102037181N1. It was approved by the Research Ethics Committee of Zanjan University of Medical Sciences (Code: ZUMS.REC.1396.138). All ethical principles were considered in this study. Before the study, the participants were informed of the study objectives and methods and were assured of the confidentiality of their 
information. All of them signed informed written consent. They were free to leave the study at any time.

\section{Funding}

This study was extracted from a MA. thesis of the first author at Department of Clinical Psychology, Faculty of Medicine, Zanjan University of Medical Sciences, Zanjan.

\section{Authors' contributions}

All authors equally contributed to preparing this article.

\section{Conflict of interest}

The authors declared no conflict of interest.

\section{Acknowledgments}

The authors would like to thank all study participants and the staff of Sohravardi Clinic in Shahid Beheshti Hospital in Zanjan City for their valuable cooperation.

\section{References}

Aazami, Y., Khanjani, M., \& Sader, M. M. (2017). [Confirmatory Factor Structure of Depression, Anxiety and Stress Scale in students (Persian)]. Journal of Mazandaran University of Medical Sciences, 27(154), 94-106. http://jmums.mazums. ac.ir/article-1-9617-en.html

Aldao, A., \& Nolen-Hoeksema, S. (2010). Specificity of cognitive emotion regulation strategies: A transdiagnostic examination. Behavior Research and Therapy, 48, 974-83. [DOI:10.1016/j.brat.2010.06.002] [PMID]

American Psychiatric Association. (2013). Diagnostic and Statistical Manual of Mental Disorders, Virginia: American Psychiatric Association. [DOI:10.1176/appi. books.9780890425596

Angelakis, E., Stathopoulou, S., Frymiare, J. L., Green, D. L. Lubar, J. F., \& Kounios, J. (2007). EEG neurofeedback: a brief overview and an example of peak alpha frequency training for cognitive enhancement in the elderly. The Clinical Neuropsychologist, 21(1), 110-29. [DOI:10.1080/13854040600744839] [PMID]

Barreiros, A. R., Almeida, I., Baía, B. C., \& Castelo-Branco, M. (2019). Amygdala modulation during emotion regulation training with fmri-based neurofeedback. Frontiers in $\mathrm{Hu}$ man Neuroscience, 13, 89. [DOI:10.3389/fnhum.2019.00089] [PMID] [PMCID]

Besharat, M. A., (2013). [Mediation effect of self-regulation on the relationship between attachment styles and alexithymia (Persian)]. Journal of Psychological Achievements, 20(2), 18-39. https:/ / psychac.scu.ac.ir/article_11766_01a2b9d6ab1b1064 e7cf7236f90f4286.pdf?lang=en
Borkovec, T. D., Ray, W. J., \& Stober, J. (1998). Worry: A cognitive phenomenon intimately linked to affective, physiologi$\mathrm{cal}$, and interpersonal behavioral processes. Cognitive Therapy and Research, 22(6), 561-76. [DOI:10.1023/A:1018790003416]

Brown, D., Scheflin, A. W., \& Hammond, D. C. (1998). Memory, trauma treatment, and the law. New York: WW Norton \& Co. https://psycnet.apa.org/record/1997-36532-000

Caria, A., Veit, R., Sitaram, R., Lotze, M., Weiskopf, N., \& Grodd, W., et al. (2007). Regulation of anterior insular cortex activity using real-time fMRI. Neuroimage, 35(3), 1238-46. [DOI:10.1016/j.neuroimage.2007.01.018] [PMID]

Cha, J., Greenberg, T., Carlson, J. M., DeDora, D. J., Hajcak, G., \& Mujica-Parodi, L. R. (2014). Circuit-wide structural and functional measures predict ventromedial prefrontal cortex fear generalization: implications for generalized anxiety disorder. Journal of Neuroscience, 34(11), 4043-53. [DOI:10.1523/ JNEUROSCI.3372-13.2014] [PMID] [PMCID]

Critchley, H. D. (2005). Neural mechanisms of autonomic, affective, and cognitive integration. Journal of Comparative Neurology, 493(1), 154-66. [DOI:10.1002/cne.20749] [PMID]

Demos, J., \& Masterpasqua, F. (2005). Changing brainwaves in psychological practice. Psyccritiques, 50(26). [DOI:10.1037/051491]

American Psychiatric Association. (2013). Diagnostic and statistical manual of mental disorders (DSM-5®). Washington, D.C. American Psychiatric Pub. https://books.google.com/ books?

Dyck, M., Loughead, J., Kellermann, T., Boers, F., Gur, R. C. \& Mathiak, K. (2011). Cognitive versus automatic mechanisms of mood induction differentially activate left and right amygdala. Neuroimage, 54(3), 2503-13. [DOI:10.1016/j. neuroimage.2010.10.013] [PMID]

Etkin, A., Prater, K. E., Hoeft, F., Menon, V., \& Schatzberg, A. F. (2010). Failure of anterior cingulate activation and connectivity with the amygdala during implicit regulation of emotional processing in generalized anxiety disorder. American Journal of Psychiatry, 167(5), 545-54. [DOI:10.1176/appi. ajp.2009.09070931] [PMID] [PMCID]

Faridnia, M., Shojaei, M., \& Rahimi, A. (2012). The effect of neurofeedback training on the anxiety of elite female swimmers. Annals of Biological Research, 3(2), 1020-8. https:// www.scholarsresearchlibrary.com/abstract/the-effectof-neurofeedback-training-on-the-anxiety-of-elite-femaleswimmers-10185.html\#: : text $=$ The $\%$ 20results $\%$ 20revealed $\% 20$ that $\% 20 \mathrm{in}$, anxiety $\% 20 \mathrm{in} \% 20$ elite $\% 20$ female $\% 20$ swimmers.

Gross, J. J., \& John, O. P. (2003). Individual differences in two emotion regulation processes: implications for affect, relationships, and well-being. Journal of Personality And Social Psychology, 85(2), 348. [DOI:10.1037/0022-3514.85.2.348] [PMID]

Hammond, D. C. (2005). Neurofeedback with anxiety and affective disorders. Child and Adolescent Psychiatric Clinics, 14(1), 105-23. [DOI:10.1016/j.chc.2004.07.008] [PMID]

Heller, W., Etienne, M. A., \& Miller, G. A. (1995). Patterns of perceptual asymmetry in depression and anxiety: implications for neuropsychological models of emotion and psychopathology. Journal of Abnormal Psychology, 104(2), 327-33. [DOI:10.1037/0021-843X.104.2.327] [PMID] 
Hölzel, B. K., Hoge, E. A., Greve, D. N., Gard, T., Creswell, J. D., \& Brown, K. W., et al. (2013). Neural mechanisms of symptom improvements in generalized anxiety disorder following mindfulness training. NeuroImage: Clinical, 2, 448-58. [DOI:10.1016/j.nicl.2013.03.011] [PMID] [PMCID]

Jakupcak, M., Salters, K., Gratz, K. L., \& Roemer, L. (2003). Masculinity and emotionality: An investigation of men's primary and secondary emotional responding. Sex Roles, 49(3-4), 11120. [DOI:10.1023/A:1024452728902]

Kandel ER, Schwartz JH, Jessell TM, Biochemistry Do, Jessell MBT, Siegelbaum S, et al. (2000). Principles of neural science. New Yor: McGraw-hill:

Kuskowski, M. A., Malone, S. M., Kim, S. W., Dysken, M. W., Okaya, A. J., \& Christensen, K. J. (1993). Quantitative EEG in obsessive-compulsive disorder. Biological Psychiatry, 33(6), 423-30. [DOI:10.1016/0006-3223(93)90170-I]

Liu, W. J., Yin, D. Z., Cheng, W. H., Fan, M. X., You, M. N., \& Men, W. W., et al. (2015). Abnormal functional connectivity of the amygdala-based network in resting-state FMRI in adolescents with generalized anxiety disorder. Medical Science Monitor: International Medical Journal of Experimental And Clinical Research, 21, 459. [DOI:10.12659/MSM.893373] [PMID] [PMCID]

Mennin, D. S., Heimberg, R. G., Turk, C. L., \& Fresco, D. M. (2005). Preliminary evidence for an emotion dysregulation model of generalized anxiety disorder. Behaviour Research and Therapy, 43(10), 1281-310. [DOI:10.1016/j.brat.2004.08.008] [PMID]

Mennin, D. S., Turk, C. L., Heimberg, R. G., \& Carmin, C. N. (2004). Regulation of emotion in generalized anxiety disorder Cognitive Therapy Across the Lifespan: Evidence and Practice, 6089. [DOI:10.1017/CBO9781139087094.005]

Menon, V. (2011). Large-scale brain networks and psychopathology: A unifying triple network model. Trends in Cognitive Sciences, 15(10), 483-506. [DOI:10.1016/j.tics.2011.08.003] [PMID]

Monk, C. S., Telzer, E. H., Mogg, K., Bradley, B. P., Mai, X., \& Louro, H. M., et al. (2008). Amygdala and ventrolateral prefrontal cortex activation to masked angry faces in children and adolescents with generalized anxiety disorder. Archives of General Psychiatry, 65(5), 568-76. [DOI:10.1001/ archpsyc.65.5.568] [PMID] [PMCID]

Naeinian, M. R., Shairi, M., Sharifi, M., \& Hadian, M. (2011). To study reliability and validity for a brief measure for assessing Generalized Anxiety Disorder (GAD-7).Continuous Positive Airway Pressure, 2(4), 41-50. https://www.sid.ir/en/journal/ ViewPaper.aspx?ID=299776

Othmer, S., Othmer, S., \& Legarda, S. B. (2011). Clinical neurofeedback: Training brain behavior. Treat Strategies-Pediatr Neurol Psychiatry, 2, 67-73.

Paret, C., Kluetsch, R., Ruf, M., Demirakca, T., Hoesterey, S. \& Ende, G., et al. (2014). Down-regulation of amygdala activation with real-time fMRI neurofeedback in a healthy female sample. Frontiers in Behavioral Neuroscience, 8, 299. [DOI:10.3389/fnbeh.2014.00299] [PMID] [PMCID]

Simpson, H. B., Tenke, C. E., Towey, J. B., Liebowitz, M. R., \& Bruder, G. E. (2000). Symptom provocation alters behavioral ratings and brain electrical activity in obsessive-compulsive disorder: a preliminary study. Psychiatry Research, 95(2), 149 55. [DOI:10.1016/S0165-1781(00)00177-3]
Spitzer, R. L., Kroenke, K., Williams, J. B., \& Löwe, B. (2006) A brief measure for assessing generalized anxiety disorder: The GAD-7. Archives of Internal Medicine, 166(10), 1092-7. [DOI:10.1001/archinte.166.10.1092] [PMID]

Thatcher, R. W. (2010). Validity and reliability of quantitative electroencephalography. Journal of Neurotherapy, 14(2), 122-52 [DOI:10.1080/10874201003773500]

Turk, C. L., Heimberg, R. G., Luterek, J. A., Mennin, D. S., \& Fresco, D. M. (2005). Emotion dysregulation in generalized anxiety disorder: A comparison with social anxiety disorder. Cognitive Therapy and Research, 29, 89-106. [DOI:10.1007/s10608-005-1651-1]

Wiedemann, G., Pauli, P., Dengler, W., Lutzenberger, W., Birbaumer, N., \& Buchkremer, G. (1999). Frontal brain asymmetry as a biological substrate of emotions in patients with panic disorders. Archives of General Psychiatry, 56(1), 78-84. [DOI:10.1001/archpsyc.56.1.78] [PMID]

Young, K. D., Zotev, V., Phillips, R., Misaki, M., Drevets, W. C., \& Bodurka, J. (2018). Amygdala real-time functional magnetic resonance imaging neurofeedback for major depressive disorder: A review. Psychiatry and Clinical Neurosciences, 72(7), 466-81. [DOI:10.1111/pcn.12665] [PMID] [PMCID]

Young, K. D., Zotev, V., Phillips, R., Misaki, M., Yuan, H., \& Drevets, W. C., et al. (2014). Real-time FMRI neurofeedback training of amygdala activity in patients with major depressive disorder. PloS One, 9(2), e88785. [DOI:10.1371/journal. pone.0088785] [PMID] [PMCID]

Zoefel, B., Huster, R. J., \& Herrmann, C. S. (2011). Neurofeedback training of the upper alpha frequency band in EEG improves cognitive performance. Neuroimage, 54(2), 1427-31. [DOI:10.1016/j.neuroimage.2010.08.078] [PMID] 